\title{
BMJ Open Experiences with, perceptions of and attitudes towards traditional Korean medicine (TKM) in patients with chronic fatigue: a qualitative, one-on-one, in-depth interview study
}

\author{
Haeng-Mi Son, ${ }^{1}$ Eun Young Park, ${ }^{2}$ Duck Hee Kim, ${ }^{3}$ Eunjeong Kim, ${ }^{4}$ Mi-Suk Shin, ${ }^{5}$ \\ Tae-Hun $\mathrm{Kim}^{6}$
}

To cite: Son H-M, Park EY, Kim DH, et al. Experiences with, perceptions of and attitudes towards traditional Korean medicine (TKM) in patients with chronic fatigue: a qualitative, one-on-one, indepth interview study. BMJ Open 2015;5:e006178. doi:10.1136/bmjopen-2014006178

- Prepublication history for this paper is available online. To view these files please visit the journal online (http://dx.doi.org/10.1136/ bmjopen-2014-006178).

Received 13 March 2015 Revised 5 August 2015 Accepted 12 August 2015

CrossMark

For numbered affiliations see end of article.

Correspondence to Professor Tae-Hun Kim; rockandmineral@gmail.com

\section{ABSTRACT}

Objectives: To explore perceptions and experiences of patients with chronic fatigue with traditional Korean medicine (TKM) and their motivation for choosing TKM.

Design: Qualitative, one-on-one, in-depth interview study.

Setting: Primary TKM hospitals in Seoul, Incheon and Daejeon, South Korea.

Results: 15 patients with chronic fatigue were interviewed in this study. Patients with chronic fatigue experienced physical and psychological symptoms that resulted in severe difficulties associated with routine daily activities. The motivations for choosing TKM were primarily dissatisfaction with conventional medicine and previous positive experiences with TKM. While undergoing TKM treatment, patients found that TKM practitioners considered fatigue to be a treatable illness; also, patients felt comfortable with the doctorpatient relationship in TKM.

Conclusions: Healthcare providers need to be concerned about the symptoms of chronic fatigue to a degree that is in line with the patient's own perceptions. Korean patients with chronic fatigue choose TKM as an alternative to fulfil their long-term needs that were unmet by conventional medicine, and they are greatly positively influenced by TKM. TKM may present a possible therapy to alleviate symptoms of diseases that conventional medicine does not address and is an approach that has a considerable effect on Korean patients.

\section{INTRODUCTION}

Fatigue is generally accepted to be a combination of symptoms that is an acute response to physical or mental exertion and is characterised by recovery after rest. When fatigue symptoms continue for more than 6 months, it is defined as a chronic condition. ${ }^{1}$ Various types of illnesses are associated with fatigue. ${ }^{2}$

\section{Strengths and limitations of this study}

- For our one-on-one, in-depth interviews, we recruited interviewees through referrals from traditional Korean medicine (TKM) physicians and used a snowball sampling method, which potentially introduced a bias, favouring interviewees with positive opinions of TKM treatments.

- The limitation is that the study findings can be only applied to the Korean population that uses or is at least familiar with TKM.

However, many patients who present with severe disability in their daily lives have fatigue symptoms that cannot be explained by pathological causes. ${ }^{3}$ Chronic fatigue syndrome, a condition that is defined by a period of more than 6 months of continuous fatigue without the presence of a specific underlying disease, is prevalent among the general population in Korea. The prevalence is estimated to be $0.6-2.0 \%$, which is quite similar to that found in Western societies $(0.5-2.5 \%){ }^{4}$

Traditional Korean medicine (TKM) is a medical practice system included in the category of orthodox medicine in Korea. TKM interventions consist of herbal medicine, acupuncture, moxibustion and cupping therapies, similar to those of traditional Chinese medicine. However, TKM has developed unique medical theories, including Sasang constitutional medicine and the syndrome differentiation method based on Donguibogam, and styles of practice, including the Saam acupuncture method, that have been influenced by medical practices in other East Asian countries. ${ }^{5}$ Sasang constitutional medicine explains physiology and pathology based on the different types of 
inherited constitutions of an individual person. One patient's constitution, whether it be of the Taeyang, Taeeum, Soyang or Soeum type, does not change during their lifetime, and symptom patterns can be different based on specific constitutions, even though the pathological causes do not differ between patients. In this sense, treatment strategies are preferentially focused on the patient's specific constitution, not on the pathology, which is distinct from the practices of TCM. ${ }^{6}$ Donguibogam, written by Heo Jun in 1610 , is considered to be the canonical work on the clinical practice of TKM in Korea. ${ }^{7}$ The system of diagnosis and modality for treatment in Donguibogam is constructed on the basis of the specific Korean context. For example, all of the names of medicinal herbs were written in Hangul, the Korean alphabet, to make them easier to understand. In the book, substitutes for some herbs that do not naturally grow on the Korean peninsula are suggested. Saam acupuncture is based on a principle of the selection of acupuncture points and stimulating methods of needles based on TKM theory. As with Sasang constitutional medicine, Saam acupuncture also suggests an individualised and tailored therapeutic strategy. Saam acupuncture adopted TCM theories such as the five elements and their interactions, but detailed that the features of acupuncture practice are quite different from those of TCM. ${ }^{8} 9$

Systematic reviews on the effectiveness of complementary and alternative medicine (CAM) interventions including acupuncture, moxibustion and herbal medicines suggest that these alternative therapies may be effective in improving symptoms related to chronic fatigue. ${ }^{8} 10^{11}$ In addition, recent survey results suggest that many Korean patients have had experience with TKM for the treatment of chronic fatigue. ${ }^{12}$ However, there is no research available examining why patients prefer and select CAM interventions, what they experience during these treatment sessions, or how they are affected at the end of the sessions. The purpose of this qualitative study was to assess the personal experiences of patients with chronic fatigue administered TKM treatments. We tried to understand the patients' experience of their symptoms, the physical, psychological and social influences related to chronic fatigue, as well as their motivation for choosing TKM and their perceptions of TKM interventions.

\section{METHODS}

\section{Recruitment of interviewees}

Participants who visited TKM hospitals with symptoms of continuous or repetitive tiredness during the preceding 6 or more months were included in the pool of interview subjects. TKM hospitals are specific medical institutions in Korea where qualified TKM doctors practise, using medicinal herbs, acupuncture, moxibustion, cupping, etc, based on TKM principles. Generally, musculoskeletal disease is the most frequent reason for visiting TKM hospitals, and chronic fatigue is also one of the major reasons for visiting TKM hospitals. ${ }^{13}$ Participants were primarily recruited through referrals from physicians in local TKM hospitals in Seoul, Incheon and Daejeon, South Korea, from July to November 2012. In addition, acquaintances who were recommended by participants were also included in interviews, if appropriate. Interviewees were recruited thorough a snowball sampling method until the sample data were saturated. Research participants participated on their own initiative, and no one refused to participate in the data collection of this study. Fifteen patients with chronic fatigue were interviewed for this study. Of the participants, 12 had underlying diseases that might have been related to fatigue, 3 did not. Five patients were male, and 10 were female. The age distribution was as follows: three were in their 20s, two in their 30 s, one in their 40s, six in their 50s and three in their 60s. As for the duration of the fatigue symptoms, six had symptoms for 10 or more years, four for 5-9 years, four for 1-4 years and one for less than 1 year. All participants had previous experience with TKM treatments, such as acupuncture, moxibustion and cupping, as well as herbal medications (table 1).

\section{Data collection}

Data collection was performed using one-on-one, in-depth interviews of participants. Among all researchers, four who are experts in data collection by conducting qualitative research interviews participated in the interview process. For each interview, one single researcher conducted it alone and every researcher conducted 3-5 individual interviews. The interviews were audio recorded by the interviewers, and the contents were transcribed verbatim. The interview questions comprised the main questions and any additional questions asked by the research team after internal discussion. The main questions were open-ended, such as 'Tell us about your experience with TKM treatment of chronic fatigue'. The time spent on each interview was between 1 and $2 \mathrm{~h}$. Interviews were conducted in places where participants felt comfortable to be interviewed, such as a quiet café, a hospital conference room or a participant's home. To clarify interview components that were unclear and to supplement the interview for some participants $(\mathrm{B}, \mathrm{J}, \mathrm{O})$, additional phone interviews were conducted (table 2). The content of the interviews was considered to be saturated when no novel content was obtained from participants. Three part-time students worked on the transcription of the gathered interview data, whereas the actual research interviewer confirmed the transcription contents in the text.

\section{Data analysis}

Previous surveys on chronic fatigue syndrome only dealt with prevalence, physical and emotional symptoms and diagnostic features from the TCM point of view. ${ }^{14}$ However, these studies did not cover the patient's 
Table 1 Characteristics of interviewees

\begin{tabular}{|c|c|c|c|c|c|}
\hline $\begin{array}{l}\text { Participant's } \\
\text { code }\end{array}$ & Sex & Underlying diseases & $\begin{array}{l}\text { Duration of } \\
\text { illness (year) }\end{array}$ & Chief symptoms & $\begin{array}{l}\text { Experience of TKM } \\
\text { treatments }\end{array}$ \\
\hline$A$ & $\mathrm{~F}$ & $\begin{array}{l}\text { Thyroid gland cancer } \\
\text { postoperative status/ } \\
\text { cholecystectomy }\end{array}$ & 3 & $\begin{array}{l}\text { Migraine, dyspepsia, } \\
\text { short-term memory loss }\end{array}$ & $\begin{array}{l}\text { Herbal medicine and } \\
\text { acupuncture }\end{array}$ \\
\hline$B$ & $\mathrm{~F}$ & None & 5 & $\begin{array}{l}\text { Headache, dyspepsia, neck } \\
\text { and shoulder pain, insomnia }\end{array}$ & $\begin{array}{l}\text { Herbal medicine and } \\
\text { acupuncture }\end{array}$ \\
\hline C & $\mathrm{F}$ & Hypertension & 10 & $\begin{array}{l}\text { Leg weakness, walking } \\
\text { difficulty, headache }\end{array}$ & $\begin{array}{l}\text { Herbal medicine, } \\
\text { acupuncture and moxibustion }\end{array}$ \\
\hline $\mathrm{D}$ & M & Angina pectoris & 40 & Headache, wasting & Herbal medicine \\
\hline$E$ & $\mathrm{~F}$ & Anaemia & 9 & $\begin{array}{l}\text { Blurred vision, periorbital } \\
\text { tenderness, neck stiffness, } \\
\text { nausea, headache }\end{array}$ & Herbal medicine \\
\hline $\mathrm{F}$ & M & Chronic bronchitis & 5 & $\begin{array}{l}\text { Heaviness in the morning, } \\
\text { wasting }\end{array}$ & $\begin{array}{l}\text { Herbal medicine and } \\
\text { moxibustion }\end{array}$ \\
\hline G & M & None & 3 & $\begin{array}{l}\text { Nasal sensitivity to smoke } \\
\text { pollution, headache, } \\
\text { difficulty speaking }\end{array}$ & $\begin{array}{l}\text { Herbal medicine and } \\
\text { acupuncture }\end{array}$ \\
\hline $\mathrm{H}$ & $\mathrm{F}$ & Uterine myoma & 10 & Headache, wasting & $\begin{array}{l}\text { Herbal medicine, } \\
\text { moxibustion and cupping } \\
\text { therapy }\end{array}$ \\
\hline 1 & M & Pyelonephritis & 10 & $\begin{array}{l}\text { Headache, palpitation, } \\
\text { tremor of hands and feet }\end{array}$ & $\begin{array}{l}\text { Herbal medicine, } \\
\text { acupuncture, moxibustion } \\
\text { and cupping therapy }\end{array}$ \\
\hline J & $\mathrm{F}$ & Diabetes/spondylosis & 5 & $\begin{array}{l}\text { Difficulty waking up in the } \\
\text { morning, lethargy, sweating } \\
\text { during sleep, anorexia }\end{array}$ & $\begin{array}{l}\text { Herbal medicine, } \\
\text { moxibustion and cupping } \\
\text { therapy }\end{array}$ \\
\hline K & M & Allergic rhinitis & 11 & Lethargy & Herbal medicine \\
\hline $\mathrm{L}$ & $\mathrm{F}$ & Gastritis & 15 & Loss of energy & $\begin{array}{l}\text { Herbal medicine, } \\
\text { acupuncture, moxibustion } \\
\text { and cupping therapy }\end{array}$ \\
\hline M & $\mathrm{F}$ & $\begin{array}{l}\text { Gastric cancer } \\
\text { postoperative status }\end{array}$ & 3 & $\begin{array}{l}\text { Blurred vision, loss of } \\
\text { energy }\end{array}$ & $\begin{array}{l}\text { Herbal medicine, } \\
\text { acupuncture and moxibustion }\end{array}$ \\
\hline $\mathrm{N}$ & $\mathrm{F}$ & Chronic gastritis & 1 & $\begin{array}{l}\text { Hearing disturbance, } \\
\text { eyestrain, stomatitis, } \\
\text { difficulty waking up }\end{array}$ & $\begin{array}{l}\text { Herbal medicine, } \\
\text { acupuncture and cupping } \\
\text { therapy }\end{array}$ \\
\hline $\mathrm{O}$ & $\mathrm{F}$ & None & 0.6 & $\begin{array}{l}\text { Feeling heavy in the head, } \\
\text { dizziness, loss of energy, } \\
\text { feeling of shoulder } \\
\text { heaviness }\end{array}$ & $\begin{array}{l}\text { Herbal medicine and } \\
\text { moxibustion }\end{array}$ \\
\hline
\end{tabular}

experience and perception of the usage of TKM. Qualitative content analysis is a research method used for the subjective interpretation of textual data through the process of coding and the identification of themes. It is a flexible and pragmatic research method ${ }^{15}$ for conducting qualitative research without any philosophical presumptions, using a specific qualitative research method. In this study, researchers applied qualitative content analysis to understand the patient's experience of suffering from chronic fatigue and to understand the usefulness of TKM treatment without any philosophical presumptions of the specific qualitative research methods. The goal of content analysis is to provide knowledge and understanding of the phenomenon being studied. ${ }^{15}$ All of the four researchers who conducted the interviews had participated in the overall process of whole data analysis: first, each researcher analysed the transcription of the gathered interview individually and after that they shared it with other researchers. After consecutive discussions for the reconciliation of their opinions, the researchers confirmed the concepts and generalised the data with categories. Data analysis was performed by repeatedly reading all data, line by line, to achieve data immersion. Codes were generated from the data and were sorted into categories and subcategories based on the level of abstractness and how different codes were related and linked. Relationships were identified through a comparison of the similarities and differences between the categories and subcategories. We present concepts, subcategories and categories in detail, as well as a coding tree (table 3 and figure 1 ). 
Table 2 Interview schedule

\begin{tabular}{|c|c|c|c|c|c|c|}
\hline \multirow{2}{*}{$\begin{array}{l}\text { Participant's } \\
\text { code }\end{array}$} & \multirow[b]{2}{*}{ Sex } & \multicolumn{2}{|l|}{ Interview } & \multicolumn{3}{|c|}{ Additional interview } \\
\hline & & Frequency & Duration (min) & Methods & Frequency & Duration (min) \\
\hline$A$ & $\mathrm{~F}$ & 1 & 95 & & & \\
\hline B & $\mathrm{F}$ & 1 & 60 & Telephone & 1 & 15 \\
\hline C & $\mathrm{F}$ & 1 & 70 & & & \\
\hline $\mathrm{D}$ & $M$ & 1 & 120 & & & \\
\hline$E$ & $\mathrm{~F}$ & 1 & 90 & & & \\
\hline$F$ & M & 1 & 60 & & & \\
\hline G & M & 1 & 60 & & & \\
\hline $\mathrm{H}$ & $\mathrm{F}$ & 1 & 90 & & & \\
\hline I & $M$ & 1 & 60 & & & \\
\hline J & $\mathrm{F}$ & 1 & 100 & Telephone & 1 & 15 \\
\hline K & M & 1 & 60 & & & \\
\hline $\mathrm{L}$ & $\mathrm{F}$ & 1 & 80 & & & \\
\hline M & $\mathrm{F}$ & 1 & 90 & & & \\
\hline $\mathrm{N}$ & $\mathrm{F}$ & 1 & 100 & & & \\
\hline $\mathrm{O}$ & $\mathrm{F}$ & 1 & 50 & Telephone & 1 & 20 \\
\hline
\end{tabular}

\section{Ethical considerations}

The research team received written informed consent from each of the participants after the purpose and methods of the study were explained to them. Each participant had been introduced to the study by TKM doctors from the TKM hospitals and was guaranteed selfdetermination, anonymity and confidentiality. The participants were provided with incentives for their participation.

\section{Study rigour}

To establish the rigour of this study, the research team considered the credibility, auditability and confirmability ${ }^{16}$ of each patient's interview. In the process of extracting concepts and categories from the data utilising a coding scheme, discussions were continued until an agreeable conclusion was reached among the researchers regarding the further elaboration of the data analysis. For the overall process of data gathering and data analysis, each researcher put their best efforts to avoid bias and maintain bracketing by focusing on reflexive consideration.

The results of the study were shown to the participants to confirm the description of their experiences. The contents of this study were translated into English by a bilingual translator with specific guidance from the research team, and all research members reviewed the translated manuscript.

\section{RESULTS}

Fifteen patients with chronic fatigue were interviewed in this study. Of the participants, 12 had underlying diseases that might have been related to fatigue, 3 did not. Five patients were male, and 10 were female. The age distribution was as follows: three were in their 20s, two in their 30s, one in their 40s, six in their 50s and three in their 60s. As for the duration of fatigue symptoms, six had symptoms for 10 or more years, four for 5-9 years, four for 1-4 years and one for less than 1 year. All participants had previous experience with TKM treatments, such as acupuncture, moxibustion and cupping, as well as herbal medications (table 1).

Patients with chronic fatigue experienced chronic symptoms due to physical factors and factors that characteristically cause chronic fatigue. Participants were unable to conduct normal daily activities due to their physical and psychological symptoms. When experiencing improvements in their chronic fatigue symptoms after TKM treatment, participants recognised that TKM was more appropriate than Western medicine for treating chronic fatigue. By experiencing chronic fatigue, participants realised the importance of the self-management of their health in their daily lives (figure 1).

\section{Causes of fatigue \\ Physical factors}

The interviewees generally recognised that their physical condition was related to innate weakness, ageing and underlying disease as well as fatigue. However, some participants felt that they did not pay much attention to their physical condition due to overconfidence in their health, which might be attributed to their symptoms. Some participants engaged in an excessive amount of exercise, while others noted that bad eating habits, such as frequently eating out or consuming ready-made foods, were related to fatigue. Additionally, participants thought that stress resulting from excessive household chores or workloads was the cause of fatigue.

Even though I managed to endure, when I was young I was always tired due to my feeble constitution, which has been present ever since my childhood...now I have weakened and therefore feel more tired and find it is more difficult to endure due to a lack of adaptability and immunity. (Participant F, M/54) 
Table 3 Generation and elaboration of categories, subcategories and concept

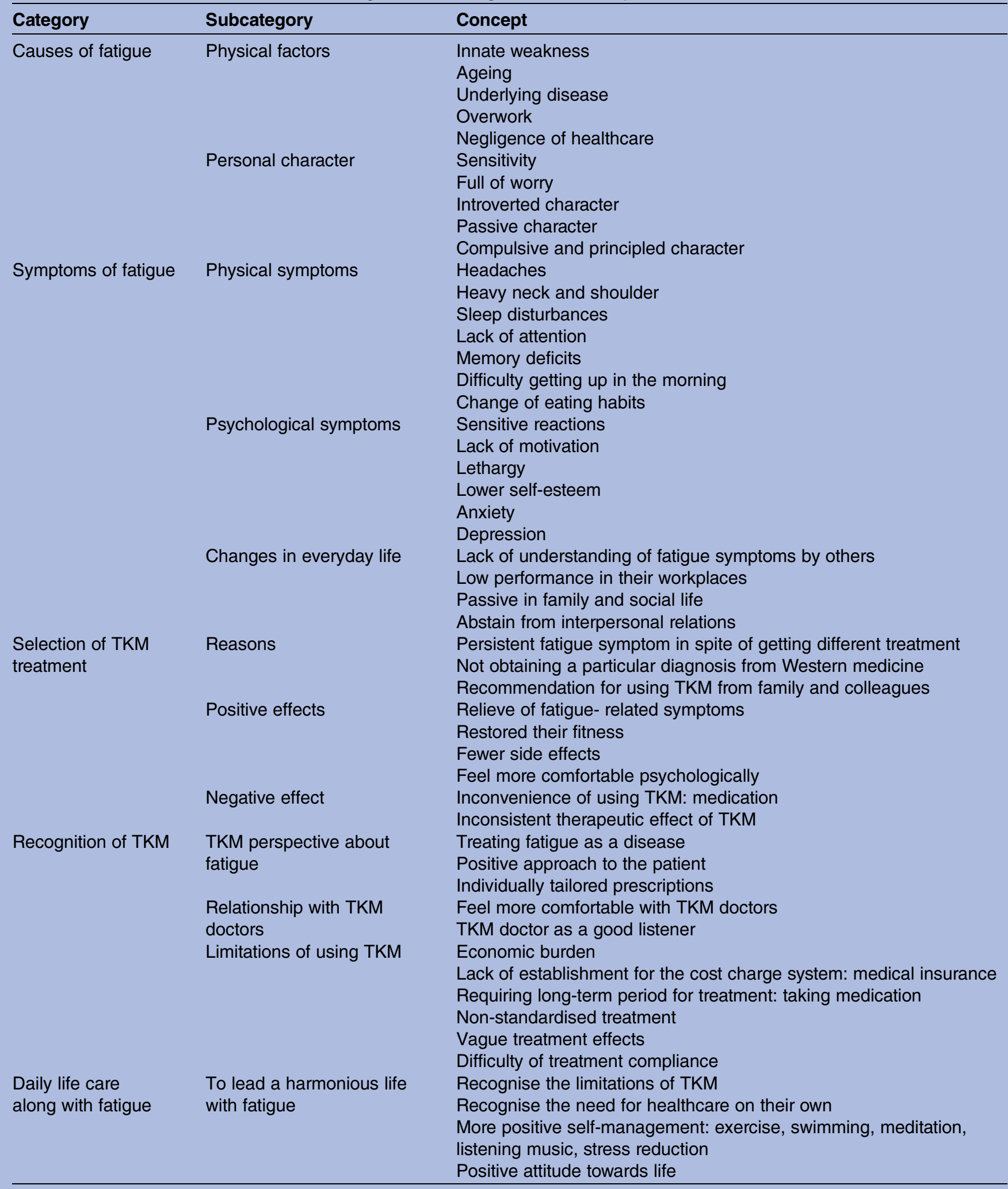

TKM, traditional Korean medicine.

\section{Personalities}

Most of the participants found clues to the cause of their fatigue in their personal characteristics. They reported that they were sensitive to everything, full of worry, introverted and passive. Thus, they claimed that mental fatigue originated largely from their situation and because they were not able to express their thoughts and felt that they should conceal them. Moreover, some 


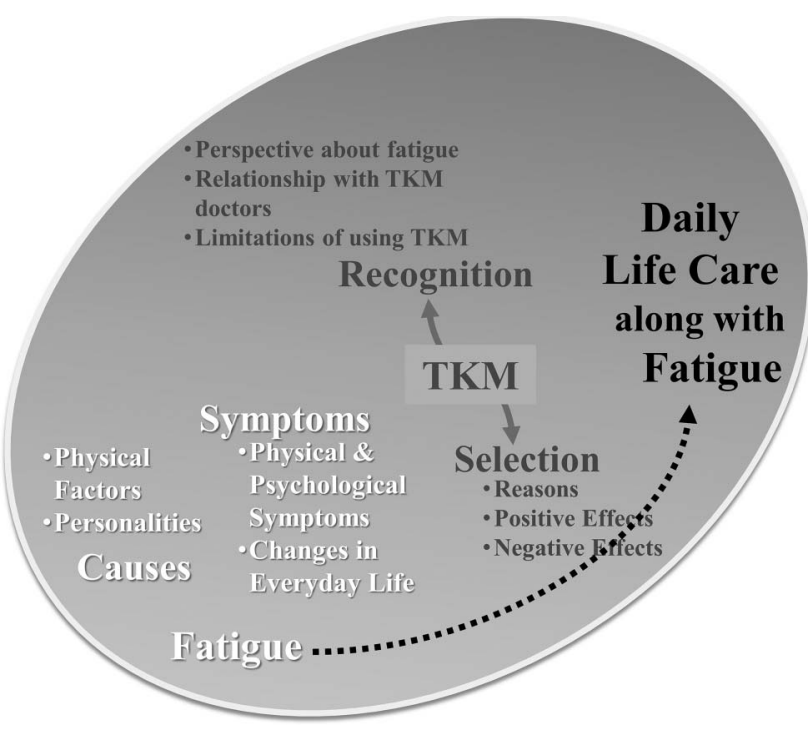

Figure 1 Relationships between categories of usage of traditional Korean medicine (TKM) in patients with chronic fatigue (coding tree).

interviewees had compulsive and self-restricting characteristics that made them follow strict principles, placing a considerable burden on their daily lives.

I admit that it is difficult to sleep when I have some concerns, because I am sensitive. When my parents-in-law were staying with us, I often woke up in the middle of the night with concerns about what I should serve them in the morning. (Participant $\mathrm{C}, \mathrm{F} / 66$ )

As for my personality, I excessively care about what would normally be overlooked. That is to say, I tend to keep my promises...if I make a promise, I do my best to the last drop of my blood. (Participant H, F/50)

\section{Symptoms of fatigue}

\section{Physical and psychological symptoms}

The participants experienced physical and psychological fatigue symptoms. They reported physical symptoms such as headaches, sleep disturbances, attention and memory deficits, and difficulty getting up in the morning. In addition, some of the participants indicated that they had a depressed emotional state described as 'difficulty saying even a word', 'difficulty breathing due to severe headache', 'the feeling of being buried, due to a lack of vigour', 'feeling sluggish' and 'feeling bad'. One participant reported that her children gave her limb massages to relieve her fatigue symptoms.

I just can't do anything. I just can't. When a headache attacks, I must simply sleep without doing anything. Frankly speaking, it occurs so severely that I must lay myself down. (Participant I, M/28)

I wake up repeatedly after one or two hours of sleep; however, I fall asleep shortly afterward, and the total amount of time sleeping is similar to that of other people. Things are so repetitive that I just keep dreaming in the middle of sleeping and hence feel sluggish when I get up in the morning, and because of this, I am more tired in the daytime. I have the feeling of walking in a fog and the feeling of wind blowing in my head...I always have heavy shoulders. It is as if a child is riding on my shoulders. (Participant B, F/29)

Participants experienced sensitive reactions to surrounding stimuli and emotional changes. Such psychological symptoms often intensified into demotivation, lower self-esteem and severe depression.

Even in a very routine conversation, I feel my husband annoying me even though he is just talking as usual. I've been arguing with him almost every day because I speak to him badly due to my illness. (Participant J, F/35)

I was driven into a state in which I didn't want to eat, didn't have any desires, and felt depressed...left alone with teardrops. (Participant M, F/64)

\section{Changes in everyday life}

The interviewees reported that they had difficulty being understood by others in everyday life, even though they experienced severe symptoms. The participants were disappointed by the responses of other people who stated that fatigue is merely a trivial symptom that everyone experiences normally. In particular, office workers were concerned about low performance in the workplace and did not want to be recognised as being incompetent by their co-workers and superiors. They underwent a vicious cycle in which they drank many caffeinated drinks to mitigate their symptoms of fatigue and increase their performance, which in turn caused sleep disturbances.

I keep really calm outwardly. I don't even notice anything in the mirror except that I am a little pale. My outward expression does not reflect my inner troubles, so I am very disappointed. (Participant H, F/50)

I can't help being ineffective in the afternoon because I am unable to focus. Therefore, I find caffeine drinks such as coffee and green tea helpful initially, but later I become so used to them that they keep me awake at night, hence the vicious cycle of fatigue. (Participant B, F/29)

Additionally, participants were passive in their family and social lives because they were always tired. The interviewees considered daily activities, such as eating out with their families, outdoor activities and travel, to be considerable burdens and increasingly avoided their previously enjoyed hobbies, such as exercise, which worried their families and depressed the family atmosphere. In their social lives, they tried to abstain from interpersonal relations in order to rest. As a result, the variety of their daily activities shrank and became monotonous.

Now, I continuously reduce social activities. Though I had promised to talk about business to someone, I just 
wanted him to quit and leave. I was not supposed to say "Let's quit because I am tired." Then, after the counselling session, I collapsed. (Participant D, M/64)

\section{Selection of TKM treatment}

\section{Reasons why patients sought TKM treatment}

Before receiving TKM treatment, some participants visited western medical hospitals to treat their constant fatigue but did not experience any healing effect or obtain a particular diagnosis. To avoid continuously difficult situations, they tried TKM treatments.

The reason why I decided to use oriental medical treatment was because western medical hospitals didn't recognise my symptoms, therefore I would not be cured. (Participant G, M/51)

Some participants received TKM treatment on the recommendation of family or colleagues, who introduced them to famous TKM clinics or TKM treatments.

My daughters encouraged me to take a traditional Korean medication because I was weak. (Participant $\mathrm{O}$, $\mathrm{F} / 59)$

People said that I should visit some place to be treated for fatigue because I should be in good condition. As for traditional Korean medication treatments, large centres are supposed to treat only one disease particularly well. I frequented many TKM clinics. (Participant D, M/64)

Most of the participants believed that western medical doctors treat clearly identified diseases, while TKM doctors restore patients' physical functions to produce a harmonious condition. They preferred TKM treatments because western medical treatments may have severe side effects, while TKM does not have a strong influence on the body and has few side effects. Most of the participants believed that TKM comprises a radical treatment that restores their weak body by improving their constitution or increasing their immunity. Additionally, the participants believed that TKM would be effective in the long term if they endured the relatively long treatment time while their symptoms got better or remained.

Western medicine targets only short-term effects, but I certainly feel little burden with traditional Korean medicine, even though a longer treatment is necessary compared to that of western medicine. (Participant D, M/64)

\section{Effects of TKM treatment}

Most of the participants took herbal medications to restore their fitness or to relieve their symptoms of fatigue. Most of the participants felt improved; their fatigue-related symptoms were relieved, and they felt more comfortable psychologically. Some participants relied more on TKM treatments because they enjoyed smelling herbal medications and felt that their condition improved when receiving acupuncture. Some of the participants reported that they experienced more of an effect on their symptoms when they consulted TKM doctors and received physical and relaxation therapies.

After receiving acupuncture twice a week along with traditional Korean medications, I am now almost completely restored so that I can engage in exercise activities. (Participant J, F/35)

Before regularly visiting a traditional Korean medical centre, I suffered from headaches almost every two days. Thus, headache medications were my best friends; however, I have not had to take them since visiting the traditional Korean medical centre. (Participant I, M/28)

The participants reported that they were able to bear the unpleasant taste of traditional Korean medications and the inconvenience of their administration for the sake of their treatment. Additionally, they carried out a detailed self-evaluation process regarding taking traditional Korean medications. They believed that traditional Korean medications are effective only when taken early and that the effects of these medications might occur later rather than earlier because they are restorative medications rather than cures. Additionally, the participants believed that traditional Korean medications should be taken periodically in the long term because they exert effects when taken but that they are ineffective or have reduced effects when not taken.

It seems that traditional Korean herbal medications have good effects in the early phase of a disease. It seems that their effects are better when I happen to take them in the early stages. Then, symptoms don't worsen. What I feel when taking traditional Korean medications periodically is that I don't have any difficult feelings after taking them for approximately two or three weeks; they don't cure me in two to three days, as when I take western medications. (Participant E, F/26)

However, not every participant experienced these effects of TKM treatments. Some participants were not convinced of their claimed effects or reported experiencing no effects.

Because I was still too tired, I never thought they had any effects. (Participant G, M/51)

\section{Recognition of TKM}

\section{The TKM perspective of fatigue}

Most of the participants were satisfied with the TKM approach, in which doctors treat fatigue as a disease, provide positive counselling and write a prescription for the symptoms. TKM doctors account for the causes of fatigue from the perspective of TKM and write individually tailored prescriptions.

Professor Son said that fatigue is also an illness. Fatigue is also an illness. He classified it as a type of disease. (Participant F, M/54) 
The participants tended to have more confidence in TKM if they were unsatisfied with the conventional medical doctors' diagnoses. Medical doctors are not interested in patients with fatigue because Western medicine does not acknowledge chronic fatigue as a disease; it offers treatment only when there is a precise diagnosis made based on an examination. It was recommended by western medical doctors that the participants receive a short-term treatment to relieve symptoms or improve their life habits. In particular, the participants expressed disappointment because they felt that their symptoms were not properly understood by western medical doctors.

Western medicine uses only certain results from examinations such as blood tests and X-ray scans to treat patients. I could not receive any treatment when my symptoms were outside of those results, and there are few treatments in western medicine when I am sick and suffer from pain. (Participant J, F/34)

Western medical doctors said there was nothing special, though I felt I was dying. I felt pain here and there and when I went to visit them because of my illness, I felt crazy when they said I was "OK". (Participant N, F/54)

\section{Relationship with TKM doctors}

The participants felt comfortable with traditional Korean doctors who understood their pain and listened to their concerns. They also reported that during consultations, TKM doctors performed specific physical examinations including checking their pulse before explaining to the patient the condition of their body and their disease state. The participants felt that they could freely ask questions of the TKM doctors. Some participants reported that they did not spare medical expenses because they felt TKM doctors dealt both with their illness and also their psychological state.

I am much more familiar with traditional Korean medical doctors. I can get close to them, feeling no distance between us, so I can say anything and feel they will listen to anything I say. Usually, when you have something to ask, you cannot say anything for fear of what the western medical doctor will say. (Participant M, F/64)

When visiting a traditional Korean medical clinic, I have a doctor examining my pulse, and I listen to everything the doctor is saying. I consult him to be informed of what I've been ignorant of. When the professor says it will be better in this way, I am convinced and come to know what I have been ignorant of. Additionally, it prevents illness. (Participant L, F/59)

\section{Limitations of TKM treatment}

Since the main treatment for chronic fatigue involves taking TKM, the participants felt more economic burden with TKM than with Western medicine. Furthermore, their economic burden increases because the National Health Insurance does not cover TKM; the non- establishment of the charge system in TKM has been a cause for shock with regard to treatment expenses.

You know health insurance does not cover TKM. The cost is 70,000 80,000 KRW (62 70 US dollars) per visit. It takes $150,000 \mathrm{KRW}$ (132 US dollars) to visit a clinic twice a week. In addition, as for medications, you should expect to pay 500,000 600,000 KRW (440 528 US dollars) for two weeks' doses. Therefore, you will spend 1,200,000 1,300,000 KRW (1055 1143 US dollars). Consequently, the poor cannot afford it. As a matter of fact, the government should provide welfare for this and not for useless things. (Participant D, M/64)

Participants reported that TKM is problematic and that they encounter difficulties in taking care of their oral medications over the long period of treatment. They also noted that there are limitations in fully relying on TKM, as its principles and mechanisms of treatment are not standardised and its treatment effects are vague. Additionally, they suggested that it is necessary to explore methods of treatment in areas where Western medicine cannot provide cures and to improve medical services that are easily accessed by all socioeconomic groups, as in the case of Western medicine.

They can standardise TKM by clearing up vague and equivocal parts given that once upon a time, Sir Heo Jun had established a system during the Joseon Dynasty. It is ridiculous for modern people to say that they cannot provide standardised treatments. They pull tricks to do things on their own. They never consider things from the perspective of consumers. (Participant G, M/51)

\section{Daily life care along with fatigue}

The participants believed that they needed to manage their healthcare on their own to lead a harmonious life with fatigue, as fatigue is a disease that they cannot help living with. They recognised the limitations of TKM and were therefore proactively trying to take care of their health, so that they could prevent the vicious cycle of fatigue by maintaining their improved condition after treatment.

I admit fatigue will live long; that is to say, it is a partner, a familiar partner. Should I say it's like sleeping with the enemy? As you know, it is a thing that you cannot help being with though you hate it and want to get rid of it. It feels like 20 30 years of marriage or a mom and dad-like feeling. Though I hate it, I can't help it as I have been cursed with fatigue. I feel like I should negotiate with it during my life. (Participant E, F/26)

I get better if I am treated. I've felt that I should make efforts to change my life habits by not being dependent solely on the treatment. I should be engaged in selfmanagement in order to avoid such a degree of chronic fatigue. (Participant J, F/35)

The participants made efforts to have a positive attitude towards life, to practise good healthcare on their own and to be engaged in more positive self- 
management in terms of stress management, exercise, swimming, meditation, etc. Most of them found pleasure in their mind and tried to be grateful for life. Additionally, they made meditation a part of their life and controlled their amount of exercise in consideration of their condition.

Now, I will live in pleasure. It seems that it is good for my health if I am pleased. (Participant H, F/50)

As I get severely tired, I consider it when I exercise. So, I will exercise three times when I used to do it 5 times before. I quit when I feel tired. That way, I expect that I will get better. (Participate G, M/51)

\section{DISCUSSION}

We found that patients with chronic fatigue believed that the development of their illness was due to physical degradation caused by underlying diseases, the ageing process or introverted personal characteristics. They experienced physical and psychological symptoms associated with fatigue that resulted in severe difficulties in relation to their daily routine activities. The motivation for choosing TKM was dissatisfaction with conventional medicine and previous positive experiences with TKM treatment of the patients themselves or their caregivers. During TKM treatment, patients found that TKM practitioners considered fatigue to be a treatable illness, and the former felt comfortable with the doctor-patient relationship in TKM practice. The economic burden and scarcity of scientific evidence were regarded as limitations to the utilisation of TKM. Finally, patients recognised their fatigue and took it to be a 'familiar partner' that lives with them for their entire lifetime.

The strengths of this study are its exploration of the patients' perception and experience of chronic fatigue and the utilisation of TKM. Previous studies have reported that patients with chronic fatigue tend to utilise CAM in Western society. ${ }^{8}$ According to a recent survey study, in Korea, many patients with chronic fatigue also use nonconventional medical treatments. ${ }^{4}$ However, this study discussed the perception of fatigue in patients and their motivations regarding their selection of TKM to relieve their symptoms. In our qualitative research, we first explored the perceptions and personal experiences of TKM patients and tried to ascertain what they considered and expected when coping with chronic fatigue. Second, the motivation for choosing alternative care in patients with chronic fatigue was observed in the Korean context. Although it is controversial, the main reasons for choosing CAM practitioners are reported to be dissatisfaction with conventional treatments and preference for the ideology of alternative therapies, which in Western societies represent a holistic attitude towards healthcare. ${ }^{17} 18$ The motivation of Korean patients with chronic fatigue was associated with non-compliance or discontent with conventional treatment, as is the case in Western societies. Interestingly, patients had the belief that TKM has the benefit of improving constitutional weakness, which was accepted as an imaginary pathology from which chronic fatigue originates and is the reason why conventional medicine was not effective in improving their symptoms. In addition, previous positive experiences with the use of TKM by patients or their caregivers strengthened this belief. These concepts might be based on Korean-specific healthcare ideals. In Korea, TKM is not merely an alternative medicine; it is a medical system that has been practised throughout Korean history and currently constitutes a major part of the healthcare system, along with conventional medicine. Two independent educational and practice systems exist based on exclusive license classifications in Korea. ${ }^{19}$ Owing to this clinical situation, patients with chronic fatigue seem to visit TKM clinics not as a counterplan to conventional medicine but as the optimal choice among the possible treatments. From this study, we also found that the patient's belief was strong enough to endure the longterm and sometimes painful interventions such as burning injuries during TKM. This concept was similarly observed in our previous qualitative research concerning patients' experience of moxibustion for chronic knee osteoarthritis; even though moxibustion may introduce severe adverse events, including burn wounds, patients continued the moxibustion with moderate to high intensity. ${ }^{20}$ How beliefs regarding TKM are formulated and reinforced in the Korean population needs to be examined in future studies, alongside studies on the motivation for choosing TKM treatment and the perceptions of TKM.

This study has limitations. Although interviews were conducted until the data reached saturation, the generalisability of this study cannot be assured for several reasons. Patients who did not want TKM treatment or dropped out during the treatment course may represent those with an opposing perception to that of the pro-TKM patients. We included patients with chronic fatigue referred by TKM doctors in this study, which might introduce a selection bias. TKM is mainly practised in Korea, so the study results need to be carefully interpreted in reference to patients with different characteristics such as racial background, educational or social status. Another limitation is the obscurity of the definition of the study population. Chronic fatigue can originate from diverse mental or physical conditions. ${ }^{21}$ The severity and importance of symptoms and their impact on the daily lives of patients are not the same for all patients. In this study, we intended to explore the perception and motivation of patients using TKM as a basic step towards understanding TKM users. Owing to the difficulty in recruiting patients who had both fatigue lasting more than 6 months and experience with TKM therapies, we used a strategy that adopted a broader disease definition of chronic fatigue. Our study included more female patients than male patients, which might affect the study results. Future research conducting interviews on TKM users with more focused and balanced patient groups, including fatigue in cancer or endocrine disease, may highlight the value of TKM in different contexts. 
Previous reports on the usage of CAM suggested that patients with chronic fatigue tend to seek CAM interventions more often than the non-fatigue group. ${ }^{22}$ In our study, we found that patients with chronic fatigue tend to use TKM as an alternative plan for coping with their symptoms. In addition, it is generally accepted that the purpose of seeking CAM treatment is related to dissatisfaction with conventional medicine. ${ }^{23}$ Our study findings also support this assumption of patients' attitudes towards CAM therapy.

We found that patients recognised chronic fatigue as an important symptom causing severe disability in their daily lives, and they sought appropriate treatments. However, they thought that physicians tended to recognise fatigue as a minor problem that did not warrant aggressive assessment and interventions commensurate with patients' requests. ${ }^{24}$ In allopathic medicine, only a partial solution is offered as a treatment for chronic fatigue, as pathophysiological mechanisms have not yet been established in many cases. ${ }^{21}$ Considering the gap between patients' expectations and clinical practice, it is no surprise that patients in Korea frequently use alternative methods of coping with their symptoms. ${ }^{12}$ Healthcare policy administrators need to keep in mind that chronic fatigue may be a serious health problem, and solutions should be proposed on the basis of the patient's perception of their condition. In addition, TCM interventions including herbal drugs, acupuncture, moxibustion and qigong therapy are likely to be effective in chronic fatigue, although evidence is currently limited due to methodological flaws of the clinical trials. ${ }^{25}$ Similar clinical effectiveness can be expected in TKM, which is a type of traditional East Asian medicine. If evidence regarding the effectiveness of TKM interventions for chronic fatigue were to be provided by rigorous studies, TKM might be accepted as an appropriate therapy to alleviate symptoms related to chronic fatigue.

\section{Author affiliations \\ ${ }^{1}$ Department of Nursing, University of Ulsan, Ulsan, Korea \\ ${ }^{2}$ College of Nursing, Gachon University, Incheon, Korea \\ ${ }^{3}$ Department of Nursing, Woosuk University, Wanju, Korea \\ ${ }^{4}$ Department of Nursing, Daedong College, Busan, Korea \\ ${ }^{5}$ Department of Nursing, Daejeon University, Daejeon, Korea \\ ${ }^{6}$ Korean Medicine Clinical Trial Center, Korean Medicine Hospital, Kyung Hee University, Seoul, South Korea}

Acknowledgements The English grammar of this manuscript was edited by American Journal Experts company.

Contributors H-MS, EYP, DHK, EJK, M-SS and T-HK conceived and participated in the design of this research. H-MS, EYP, DHK and EJK conducted the interviews and analysed the data. H-MS, EYP, DHK, EJK, M-SS and T-HK wrote the draft of this manuscript.

Funding This study was supported by the Korea Institute of Oriental medicine (K15122).

Competing interests None declared.

Patient consent Obtained.

Ethics approval The Oriental Hospital of Daejeon University Human Research Ethics Committee in Korea (IRB approval number: DJOMC-94).
Provenance and peer review Not commissioned; externally peer reviewed.

Data sharing statement No additional data are available.

Open Access This is an Open Access article distributed in accordance with the Creative Commons Attribution Non Commercial (CC BY-NC 4.0) license, which permits others to distribute, remix, adapt, build upon this work noncommercially, and license their derivative works on different terms, provided the original work is properly cited and the use is non-commercial. See: http:// creativecommons.org/licenses/by-nc/4.0/

\section{REFERENCES}

1. Klimas NG, Broderick G, Fletcher MA. Biomarkers for chronic fatigue. Brain Behav Immun 2012;26:1202-10.

2. Jason LA, Evans M, Brown M, et al. What is fatigue? Pathological and nonpathological fatigue. PM R 2010;2:327-31.

3. Afari N, Buchwald D. Chronic fatigue syndrome: a review. Am J Psychiatry 2003;160:221-36.

4. Kim $\mathrm{CH}$, Shin $\mathrm{HC}$, Won CW. Prevalence of chronic fatigue and chronic fatigue syndrome in Korea: community-based primary care study. J Korean Med Sci 2005;20:529-34.

5. Shin D. [Trends in research on the history of medicine in Korea before the modern era]. Uisahak 2010;19:1-43.

6. Yi Che-ma. Longevity \& life preservation in oriental medicine. Kyung Hee University Press, 1996.

7. UNESCO. Donguibogam: principles and practice of eastern medicine. 2010. http://portal.unesco.org/ci/en/files/27075/ 12133693253Korea_Donguibogam.pdf/Korea\%2BDonguibogam.pdf.

8. Alraek T, Lee MS, Choi TY, et al. Complementary and alternative medicine for patients with chronic fatigue syndrome: a systematic review. BMC Complement Altern Med 2011;11:87.

9. Yin $\mathrm{C}$, Park HJ, Chae $\mathrm{Y}$, et al. Korean acupuncture: the individualized and practical acupuncture. Neurol Res 2007;29(Suppl 1):S10-15

10. Adams D, Wu T, Yang $\mathrm{X}$, et al. Traditional Chinese medicinal herbs for the treatment of idiopathic chronic fatigue and chronic fatigue syndrome. Cochrane Database Syst Rev 2009(4):CD006348.

11. Wang $T$, Zhang $Q$, Xue $X$, et al. A systematic review of acupuncture and moxibustion treatment for chronic fatigue syndrome in China. Am J Chin Med 2008;36:1-24.

12. Choi $\mathrm{DH}, \mathrm{Kim} \mathrm{CH}$, Shin $\mathrm{HC}$, Park $\mathrm{YW}$, et al. Patterns of complementary and alternative medicine therapies in patients with chronic fatigue or pain. Korean J Fam Med 2009;14:182-9.

13. Park HL, Lee HS, Shin BC, et al. Traditional medicine in China, Korea, and Japan: a brief introduction and comparison. Evid Based Complement Alternat Med 2012;2012:429103.

14. Yiu YM, Qiu MY. [A preliminary epidemiological study and discussion on traditional Chinese medicine pathogenesis of chronic fatigue syndrome in Hong Kong]. Zhong Xi Yi Jie He Xue Bao 2005;3:359-62.

15. Hsieh HF, Shannon SE. Three approaches to qualitative content analysis. Qual Health Res 2005;15:1277-88.

16. Sandelowski M. The problem of rigor in qualitative research. ANS Adv Nurs Sci 1986;8:27-37.

17. Astin JA. Why patients use alternative medicine: results of a national study. JAMA 1998;279:1548-53.

18. Kelner M, Wellman B. Health care and consumer choice: medical and alternative therapies. Soc Sci Med 1997;45:203-12.

19. Ryu J, Choi B, Lim B, et al. Medical practices and attitudes of dual-licensed medical doctors in Korea. Evid Based Complement Alternat Med 2013;2013:183643.

20. Son $\mathrm{HM}, \mathrm{Kim} \mathrm{DH}, \mathrm{Kim} \mathrm{E}$, et al. A qualitative study of the experiences of patients with knee osteoarthritis undergoing moxibustion. Acupunct Med 2013;31:39-44.

21. Finsterer J, Mahjoub SZ. Fatigue in healthy and diseased individuals. Am J Hosp Palliat Care 2014;31:562-75.

22. Jones JF, Maloney EM, Boneva RS, et al. Complementary and alternative medical therapy utilization by people with chronic fatiguing illnesses in the United States. BMC Complement Altern Med 2007;7:12.

23. McFadden KL, Hernández TD, Ito TA. Attitudes toward complementary and alternative medicine influence its use. Explore (NY) 2010;6:380-8.

24. Cho HJ, Menezes PR, Hotopf M, et al. Comparative epidemiology of chronic fatigue syndrome in Brazilian and British primary care: prevalence and recognition. Br J Psychiatry 2009;194:117-22.

25. Chen R, Moriya J, Yamakawa J, et al. Traditional Chinese medicine for chronic fatigue syndrome. Evid Based Complement Alternat Med 2010;7:3-10. 